\title{
Fatigue of Binary Blend Composite Materials
}

\author{
Ekhlas Edan Kader \\ Mechanical Eng. Dep. \\ University of Diyala, Diyala, IRAQ \\ eng-ekhlas@yahoo.com \\ Received: 24-09-2017 \\ Revised: 23-11-2017 Accepted: 18-Dec.-2017 \\ http://doi.org/10.29194/NJES21020195
}

\begin{abstract}
Due to their very good mechanical properties of composite materials which led to a huge increase in its application in a lot of fields.Epoxy/ PS(polysulfide) composite materials behavior in fatigue was reported. different weight fraction of PS (2\%,4\% and6\%) were studied .Surface roughness properties of the blended composites were found for all weight fraction of PS and their fatigue properties are studied .Fatigue test was carried with rotating bending method. The loading in the test was sinusoidal wave type. The loading wave ratio is $\mathrm{R}=-1$ and the frequency of loading is applied to avoid temperature rise with a frequency equal to $5 \mathrm{~Hz}$. Fatigue strength ,fatigue life and fatigue limit of the tested composites from standard curves are calculated. The addition of PS resulted in an enhancement in the fatigue values and cause the surface roughness to decrease at a considerable rate, the blend hardness is reduced considering shore A test.
\end{abstract}

Keywords: Fatigue, surface roughness, composite materials

\section{Introduction}

There are many specific applications for polymer composites in insulation, advanced aerospace composites packaging ,protective coatings, and adhesives due to their rigidity, thermal stability flexibility, dielectric, ductility, and process ability of organic polymers. The reason make these composite used in these applications is because of high specific strength, good chemical resistance high good process ability and temperature stability. polymer composites results in a great improvements in mechanical properties, thermal stability[1-3].

The study of the failure in materials when subjected to variable cyclic loading is called Fatigue. Fatigue could be considered a slow process because the crack propagation depends on the microstructure of the isotropic materials when it is subjected to stress less than their ultimate static strength. The primary factor dominate the fatigue behavior of materials is the initiated crack which controlled the damage behavior and lead to final fracture[4,5]. Researcher study the fatigue behavior of composites to understand the specific fatigue properties, including the effect of varied testing conditions. Some of these works are.
Blackman et. Al[6]reported the behavior of modified epoxy polymers at fracture and fatigue. the study showed that an increase in toughness which led to an improvement in the cyclicfatigue behavior when silica particles is added into the epoxy. Manjunatha et. al [7] studied epoxy reinforced with glass and the tensile fatigue properties of the composite is recorded. The results showed that incorporation of silica nanoparticles and rubber micro-particles have the same effect on the fatigue performance. The addition of silica and rubber micro-particles cause $15 \%$ enhancement in fatigue limit and two to three times improvement in the life to fatigue in composite, as compared to the neat-resin matrix. .Manjunatha et. al.in another paper [8] showed an increase in the cyclic-fatigue propertis of epoxy when silica particles is added, and cause an increase in the fracture toughness due to better performance of fiber in composite. In this work, Epoxy/ PS composites, were prepared, and fatigue behavior ,hardness and surface roughness were examined. The PS particles have been a good candidate to improve the behavior of the composite.

\section{Experimental Tests \\ 2.1. Materials}

The matrix is strong coat Epoxy from DCP company(with hardener),the mixing ratio is $3: 1$ of resin/hardener with curing time is three days at room temperature, the viscosity 1.0 poise at $35 \mathrm{C}^{\circ}$ and density $1.04 \mathrm{~g} / \mathrm{cm} 3$.Tabel(1) show some technical properties. The other material is polysulfide from Thiokol company with performance date listed in Table.(2) below $[9,10]$.

Table (1): Technical properties of Epoxy

\begin{tabular}{|l|c|}
\hline Property & 1.60 \\
\hline Specific gravity & $100 \%$ \\
\hline Solid content & White, Grey and Blue \\
\hline Color & Excellent \\
\hline Abrasion resistance & $2 \mathrm{~N} / \mathrm{mm}^{2}$ \\
\hline Bond strength & $25 \mathrm{MPa}$ \\
\hline Tensile strength & \\
\hline
\end{tabular}

Table (2): Performance data of polysulfide [10]

\begin{tabular}{|c|c|}
\hline Tensile strength (ASTM d- 412) & 300 psi \\
\hline Elongation ASTM - 412) & $450-500 \%$ \\
\hline Hardness, shore a (ASTM d-2240 ) & $50-45$ \\
\hline
\end{tabular}




\begin{tabular}{|c|c|}
\hline Joint movement & $25 \%$ \\
\hline Volume solid s & $100 \%$ \\
\hline storage environment . & Dry area, $65-80^{\circ} \mathrm{f}$ \\
\hline application temperature , ambient & $40-95^{\circ} \mathrm{f}$ \\
\hline shelf life & 1 year \\
\hline${\text { Potlife, } @ 77^{\circ} \mathrm{f}}$ & 30 minutes \\
\hline
\end{tabular}

\section{Blending the composite}

pure Epoxy samples and its composites according to weight percentage of $(2 \%, 4 \%$ and $6 \%$ ) were prepared using mechanical mixer for 10 minutes(according to previous experimental works) first to disperse PS particles in the material, then the blend was left to cool at ambient temperature. after cooling down the mechanical stirring for 10 minutes is used to add hardener to the blend. Three days is required to complete curing of the mixed materials and seven days required before any test.

\section{Fatigue test}

Fatigue test samples were cut from composites sheets with dimensions according to the ASTM standard with dimensions of $250 \times 10 \times 3 \mathrm{~mm}[11]$ the device is in appendix $A$. each blend percentage were tested and the test is repeated three times for the same stress level. the average of the number of cycles, maximum and minimum displacements readings to failure[12] was taken. stress range- number of cycles to failure were analyzed according the data from S-N curves. The test was done at room temperature using cyclic bending under constant displacement equal to $20 \mathrm{~mm}$ with $5 \mathrm{~Hz}$ frequency and $\mathrm{R}=\sigma_{\min } / \sigma_{\max }=-1$. The stressed specimen bending moment $(\mathrm{Mb})$ is calculated, then bending stress $(\sigma)$ is described as:-[12]:

$$
\sigma=\frac{\mathrm{M}_{\mathrm{b}}}{\mathrm{W}}
$$

Since $W=\frac{h^{2} b}{6}$

where: $\mathrm{Mb}=$ the bending moment $(\mathrm{Nm})$.

$\mathrm{b}=$ the width of specimen $(20 \mathrm{~mm})$.

$\mathrm{h}=$ thickness of specimen.

\subsection{Fatigue strength calculation}

Basquin's Law for high cycle Fatigue was used to calculate the fatigue strength as follows [12]:-

Fatigue strength

$(\mathrm{Sf})=\mathrm{a} \mathrm{Nb}$

where $\mathrm{N}$ is cycles to failure and the constants $\mathrm{a}$ and $\mathrm{b}$ are defined by the points [13].

$$
\begin{aligned}
& a=\frac{(\mathrm{f} \text { Sut }) 2}{\mathrm{Se}} \text { and } \\
& \mathrm{b}=\frac{-1}{3} \log \left(\frac{\mathrm{f} \mathrm{Sut}}{\mathrm{Se}}\right)
\end{aligned}
$$

Endurance Limit at the critical Loading(Se):-

Se $=k^{*} k^{*}{ }^{*} c^{*} k d^{*} k e$ Se"

Surface Factor ka from standard tables.

$\mathrm{Ka}=\mathrm{a}$ (Sut)b for different weight percentage of polysulfide listed in table.(3)

Table (3): Surface Factor for different weight percentage of polysulfide

\begin{tabular}{|c|c|c|}
\hline $\mathrm{Ka}$ & Sut (MPa) & Ps\% \\
\hline 1.15 & 39.5 & 2 \\
\hline 1.10 & 35.5 & 4 \\
\hline 1.17 & 32 & 6 \\
\hline
\end{tabular}

Since Size Factor $(\mathrm{kb})=1$ from and Loading Factor $(\mathrm{kc}$ ) =1and $\mathrm{Kd}=\mathrm{Ke}=1$, for bending from standard tables[12]. Using equation--5 the endurance limits can be calculated as in tabel(4).

Table (4): Endurance limits for epoxy polysulfide blend.

\begin{tabular}{|r|c|r|}
\hline Se(Mpa) & Sut(Mpa) & Ps\% \\
\hline 75.68 & 39.5 & 2 \\
\hline 19.65 & 35.5 & 4 \\
\hline 18.82 & 32 & 6 \\
\hline
\end{tabular}

\section{Surface roughness test}

Roughness can be defined as the difference of the surface coordinates from ideal reference, or the surface distance in y-coordinates measured from a reference plane(the device picture is in appendix B). texture of a surface considering roughness height, waviness, lay and flaws. Can be evaluated. Surface roughness parameters are formed because of operation, tools and the materials. It can be calculated in 2-D or 3-D models on a path of the surface or the area. surface roughness measurement standard is ISO 25178 .it can be described by $\mathrm{Ra}$ which is the arithmetic average of absolute defined as follows[13]:-

$$
R_{a}=\frac{1}{n} \sum_{i=1}^{n}\left|y_{i}\right|
$$

\section{Hardness test}

Composites hardness properties are studied by applying indentation load normal to the specimen. The effect of PS\% addition and curing time on hardness is illustrated. Shore A test was carried out according to ASTM D 2240 .

The device readings were obtained at least three times, and then the average was considered 
for all blend samples the device picture is in appendix C[14].

\section{Results and discussion}

\subsection{Fatigue test}

Fatigue test results is shown in Fig.(1) which shows the relation of number of cycles to failure with PS\%, it is obviously noticed that number of cycles increased as the PS\%, increased because of plastic region variation of the crack-tip of epoxy /rubber particle contact. that cause a crack to deviate its path in cyclic fatigue. rubber- epoxies exhibit improved resistance to fatigue compared with the pure epoxy, because the rubber particles size smaller than the plastic region .This difference cause rubber voids /shear banding which activate plastic void growth mechanisms.

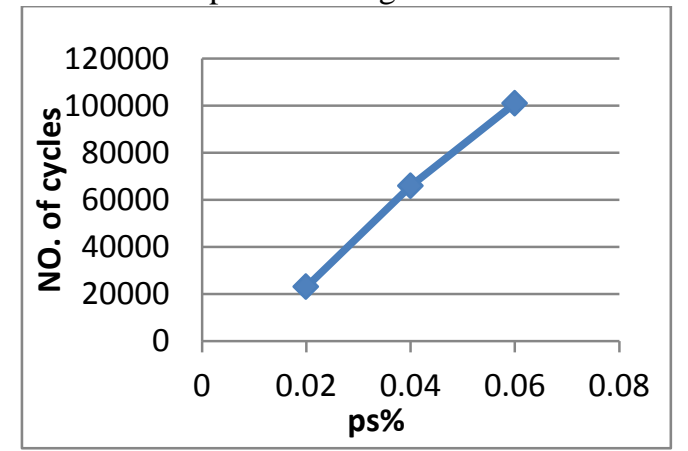

Figure (1): Fatigue number of cycles to PS\%

Fig.(2) show the number of cycles to fatigue strength, which clearly show that fatigue strength decrease as number of cycles increased. Epoxies and rubber-modified epoxies have similar crack tendency behavior. That because the difference in size between plastic region (smaller) and rubber particles size (bigger), led to failure mechanisms (cavitation/shear-banding) to operates.

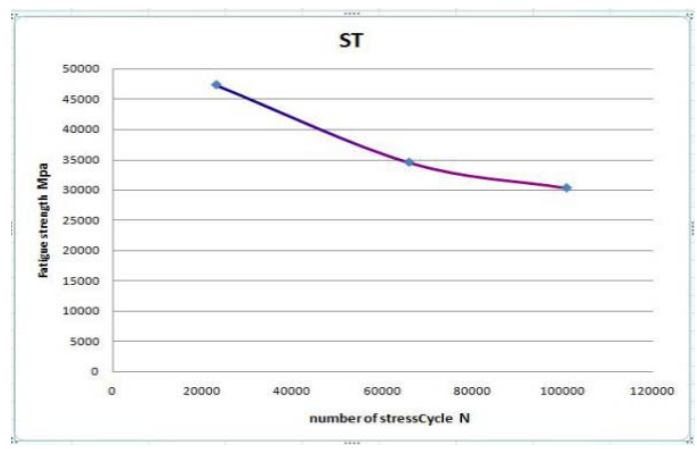

Figure (2): Number of cycles to Fatigue Strength

Table .5 shows the calculated Fatigue Strength, endurance limit for different PS

Table (5): Fatigue Strength, endurance limit for different PS\%

\begin{tabular}{|c|c|c|c|}
\hline Sf(Mpa) & Se(Mpa) & Sut(Mpa) & Ps\% \\
\hline 75.68 & 75.68 & 39.5 & 2 \\
\hline
\end{tabular}

\begin{tabular}{|c|c|c|c|}
\hline$` 40.50$ & 19.65 & 35.5 & 4 \\
\hline 21.81 & 18.82 & 32 & 6 \\
\hline
\end{tabular}

\subsection{Surface roughness results}

Surface roughness test results of Epoxy-PS with different percentages of PS were investigated. The addition of PS caused a decrease in surface roughness, as shown in figure(3), this can be attributed to the nature of the rubber and its content of sulpher with good compatibility of the two polymers with each other's.

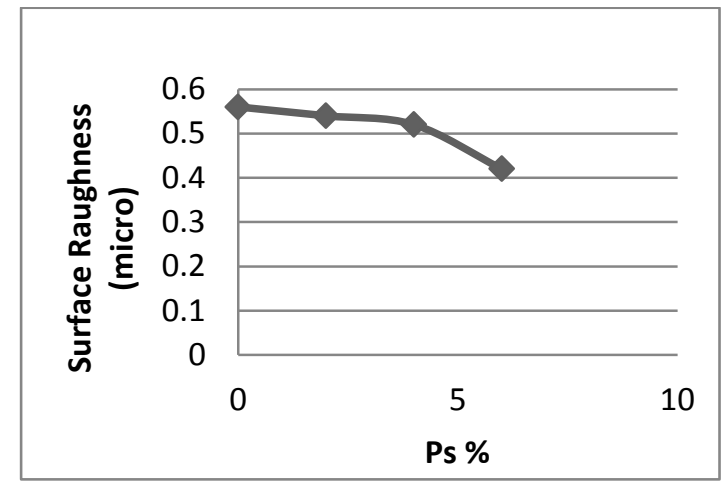

Figure (3): PS \% effect on Surface roughness of Epoxy

\subsection{Hardness test result}

Experimental results of hardness test are presented in figure(4),in which the increment of PS causes a decrease in hardness more than that of Epoxy .This is well explained by the fact that rubbers have the ability to deform and stretch plastically with a little resistance to penetration.

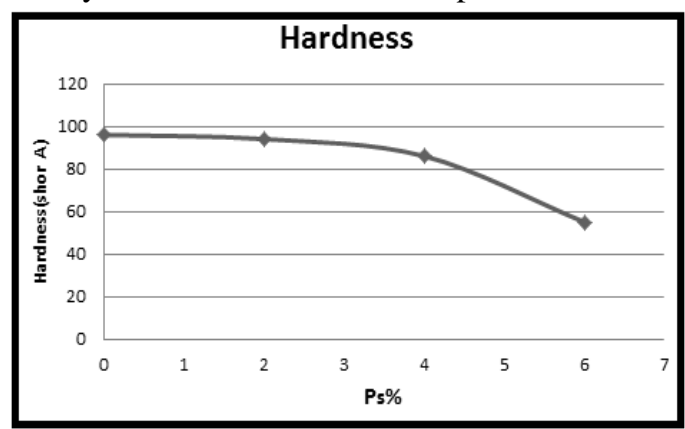

Figure (4): PS \% effect on Hardness of Epoxy

\section{Conclusions}

Epoxy blending has been experimentally studied with the following conclusions.

1-Shear mixing by mechanical stirrer is the best method for blending Epoxy with PS considering the mechanical properties results.

2- The addition of 6 wt.\% rubber micro particles to a thermosetting epoxy polymer enhance the total fatigue life(no.of cycles increased five times than before). The fatigue life was observed to increase at all the ranges of stress levels studied,

3- The fatigue crack growth rate of a rubber particle modified epoxy polymer is lower than 
that of un modified epoxy (considering time required to failure).

4. Rubber particle cavitation causes energy dissipating mechanisms. This mechanism activates the plastic deformation of the adjacent material and cause an enhancement in the fatigue life of the blend.

\section{References}

[1] R. Sarathi,"Understanding the thermal, mechanical and electrical properties of epoxycomposites" Materials Science and Engineering Vol. 445-446,PP.567-578, 2007.

[2] L. L.Zhai,"Effect of nano-Al2O3 on adhesion strength of epoxy adhesive and steel"International Journal of Adhesion \&Adhesives, Vol. 28 ,PP 2328,2008 .

[3] R.P.Singh,"Toughening of a brittle thermosetting polymer: Effects of reinforcement particle size and volume fraction"J. Mater. Sci. Vol. 37,P. 781-788, 2002

[4] W.D.Callister "Materials Science and Engineering" John Wily and Sons, Inc, London2003.

[5] T.M.Dicka,P.B.Jar"Predication of fatigue resistance of short-fiber-reinforced polymer" International Journal of Fatigue,Vol.3,PP.184191, 2009.

[6].B.R.K.Blackman" The fracture and fatigue behaviour of nano-modified epoxy polymers" MaterSci.,Vol.42 ,7049-7051, 2007
[7] C.M.Manjunath."The effect of rubber microparticles and silica nanoparticles on the tensile fatigue behavior of glass-fiber epoxy composite"J Mater Sci., Vol.44, PP.342-345, 2009.

[8] C.M. Manjunatha, "The tensile fatigue behavior of a glass fiber reinforced plastic composite using a hybrid toughened epoxy matrix" Journal of Composite Materials,Vol. 44, PP2095-2108, 2010.

[9]. Alvey, F. B.," Modification of Epoxy Polymer“, Journal of Polymer Science, Vol.7,PP. 2117, 1969.

[10]. Naim Akmal,” Polysulfide Sealants and Adhesives", Ph.D. Thesis, University of Cincinnati, Cincinnati,Ohio,U.S.A.2011

[11] K.J. Majeed"Fatigue behavior of E-glass fibers/epoxy composites" $\mathrm{PhD}$ thesis, College of Science, University of Baghdad, Baghdad, IRAQ ,2005.

[12] B. Harris "Fatigue in Composites" Woodhead Publishing Ltd, Cambridge England, 2003.

[13]. R. L. Dai and Nutt S. R.," Improving the Dispersion and Flexural Strength of rubberEpoxy

Composite”,Journalof Eur. Polymer, Vol.42, PP. 2765-2772, 2006

[14]. C.V. Srinivasa," Impact and Hardness Properties of Areca FiberEpoxyReinforcedComposites",Journal Mater. Environ. Sci.Vol 2 (4), PP.351-356, 2011.

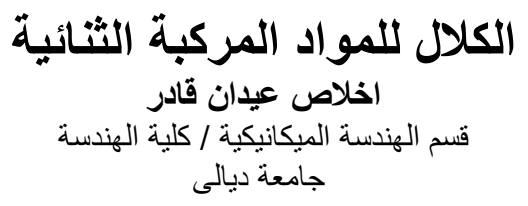

الخلاصة

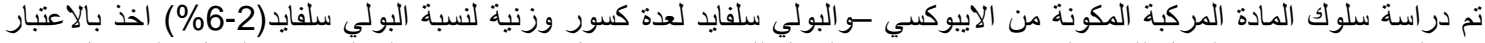

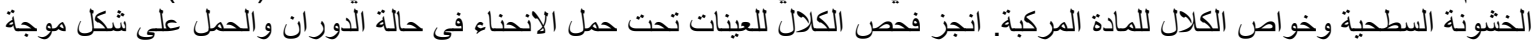

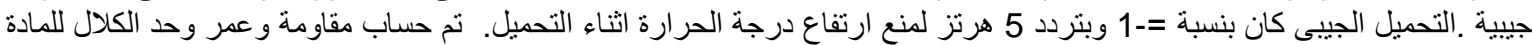

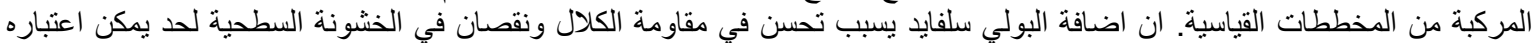

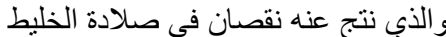

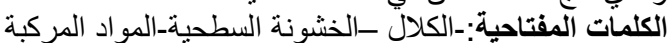

